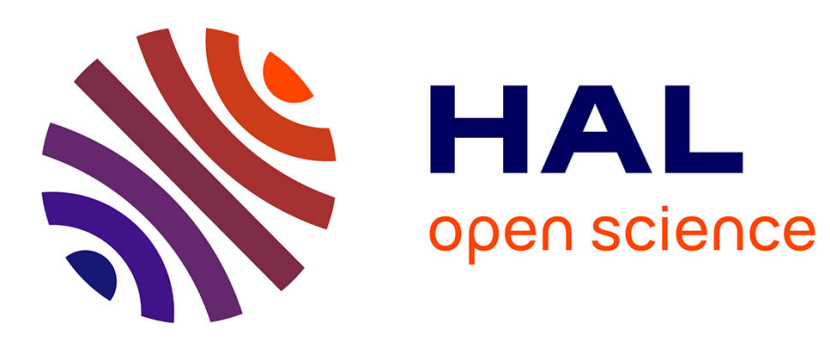

\title{
Evolution of mechanical properties of aged poly(ether ketone ketone) explained by a microstructural approach
}

Sébastien Roland, Mahdi Moghaddam, Sylvie Tencé-Girault, Bruno Fayolle

\section{To cite this version:}

Sébastien Roland, Mahdi Moghaddam, Sylvie Tencé-Girault, Bruno Fayolle. Evolution of mechanical properties of aged poly(ether ketone ketone) explained by a microstructural approach. Polymer Degradation and Stability, 2021, 183, pp.109412. 10.1016/j.polymdegradstab.2020.109412 . hal-03163245

\section{HAL Id: hal-03163245 \\ https://hal.science/hal-03163245}

Submitted on 9 Mar 2021

HAL is a multi-disciplinary open access archive for the deposit and dissemination of scientific research documents, whether they are published or not. The documents may come from teaching and research institutions in France or abroad, or from public or private research centers.
L'archive ouverte pluridisciplinaire $\mathbf{H A L}$, est destinée au dépôt et à la diffusion de documents scientifiques de niveau recherche, publiés ou non, émanant des établissements d'enseignement et de recherche français ou étrangers, des laboratoires publics ou privés. 


\title{
Evolution of mechanical properties of aged poly(ether ketone ketone) explained by a microstructural approach
}

\author{
Sébastien Roland ${ }^{\mathrm{a}}$, Mahdi Moghaddama ${ }^{\mathrm{a}}$, Sylvie Tencé-Girault ${ }^{\mathrm{a}, \mathrm{b}}$, Bruno Fayolle ${ }^{\mathrm{a}}$ \\ a PIMM, Arts et Metiers Institute of Technology, CNRS, Cnam, HESAM University, 151 boulevard de l'Hopital, 75013 Paris, France \\ ${ }^{\mathrm{b}}$ Arkema, CERDATO, Route du Rilsan, 27470 Serquigny, France
}

\begin{abstract}
A B S T R A C T
In this work, the thermo-oxidative behavior of PEKK films ( $50 \mu \mathrm{m}$ thick $)$ in solid state were investigated. Since the mechanical properties of PEKK samples, especially the strain at break, are clearly affected after long ageing time, the modifications of the PEKK structure have been monitored at the molecular and the macromolecular scales using different techniques such as gel permeation chromatography, X-Ray scattering, differential scanning calorimetry, and dynamic mechanical analysis. If the embrittlement of the PEKK specimens seems to appear due to a predominant branching/cross-linking phenomenon occurring at the macromolecular scale, crystalline morphology is also slightly modified due to a chain scission mechanism occurring simultaneously.
\end{abstract}

Keywords:

PEKK

Embrittlement

Ageing

Mechanical properties

Microstructure

\section{Introduction}

The increasing market share of composites compared to metals traditionally used in aeronautical structures has led to significant weight savings. While thermosets remain largely the majority of composite matrices compared to thermoplastics, the introduction of the latter is now being considered to increase the temperature performance of composites and facilitate their welding and recycling. Amongst the high-performance thermoplastic arylether ketones (PAEK) family, poly(ether ketone ketone) (PEKK) copolymers consisting of para and meta isomers appear to be ideal candidates as a matrix for composites since their properties are similar to poly(ether ether ketone) PEEK and can show a wider processing window [1]. Indeed, the chemical structure of PEKK can be tuned by varying the initial ratio of the constitutive repetitive units (terephthalic or isophthalic acid units, so-called T/I ratio), which modifies the crystallization kinetics and the final crystallinity ratio.

The earlier publications concerning PEKKs are associated with the first synthesis more than 30 years ago [2]. The first papers about PEKK properties are about crystallization aspects [1,3-5] where PEKKs containing terephthaloyl (T) and isophthaloyl (I) moieties have been studied in depth: the crystal structures, the polymorphism, and the crystallization kinetics have been investigated as a function of T/I ratios. During the first decade of the 20th century, only few studies are devoted to the PEKK copolymers synthesis [6] or composite applications [7]. Since 2016, several publications on PEKK are focused on crystallization kinetics modelling [8], on mechanical behavior in melt state [9] or in solid state [10]. This increase of publications number is probably related to the fact that Arkema has commercialized in 2016 the Kepstan ${ }^{\circledR}$ 6000, 7000, and 8000 having a T/I ratio of 60/40, 70/30, and 80/20, respectively.

The principal differences between the three compositions lay on their crystallization rates and their melting temperatures. These properties are increased as the $\mathrm{T}$ moiety concentration increases in the PEKK composition. For instance, for a T/I ratio of 60/40, the crystallization rate is typically lower, which allows a processing through additive manufacturing methods [11]. The T/I ratio of $70 / 30$ shows a good compromise between crystallization rate and processability, which makes it adapted to be used as matrix of carbon-fiber-based composites. Knowing amorphous PEKK 60/40 and 70/30 show high ductility at room temperature, it is noteworthy that even if the crystallinity is maximum, typically $35 \%$ for the PEKK 70/30, the polymer remains ductile even though a slight decrease of elongation at break is observed [12].

The use of polymers is often limited by a chemical ageing, such as hydrolysis or oxidation, which leads to embrittlement of these polymers. It is associated with chain scission or branching/crosslinking processes occurring during ageing. In order to characterize, to predict, or to limit this embrittlement, relationships between the chemical structure modified by ageing and the mechanical behavior, especially at failure, are required. We can note that this requirement meets the more general topic in the polymers field which is to understand the effect of the chemical structure of polymers on their fracture properties, except that, in the case of thermal ageing, the chemical structure is modified over time, which can be exceedingly long. This challenging question re- 
mains an open question, which can be tackled by using chemical ageing to modify the chemical structure of the macromolecules and to investigate the consequences of these modifications on the mechanical properties.

Let us recall some approaches to relate polymer structure and its ductility. By considering only amorphous polymers as a simple case compared to semi-crystalline polymers, two different approaches are often proposed in the literature to explain ductility below $\mathrm{T}_{\mathrm{g}}$ : the first one is to consider that ductility is associated with local mobility below $\mathrm{T}_{\mathrm{g}}$ as a sub-glass transition often called $\mathrm{T}_{\beta}$ : the more intense the latter transition, the more ductile the polymer [13]. Interestingly, this approach has been applied to linear polymers such as PMMA and its copolymers but also to networks such as epoxy thermosets. According to this approach, embrittlement of epoxies by oxidation is often associated with the sub-glass transition disappearance [14].

By considering only linear amorphous polymers, another approach is to consider that ductility is governed by the entanglement density $\left(v_{\mathrm{e}}\right)$ : the greater the entanglement density, the more ductile the polymer [15]. For these linear polymers, complete embrittlement is reached when the molar mass is below five times the molar mass between entanglements $\left(\mathrm{M}_{\mathrm{e}} \propto 1 / \nu_{\mathrm{e}}\right)$ and is thus associated with entanglements network disappearance. The critical molar mass for embrittlement is often called $\mathrm{M}_{\mathrm{C}}{ }_{\mathrm{C}}\left(\mathrm{M}_{\mathrm{C}}{ }_{\mathrm{C}} \cong 5 \mathrm{M}_{\mathrm{e}}\right)$ [16]. For a given polymer, embrittlement is then directly linked to a chain scission mechanism due to an ageing process. We have proposed to extend the latter approach to semi-crystalline polymers when they are submitted to a chain scission process. It appears that if a critical molar mass has been put in evidence when the ductile-brittle transition occurs, the physical meaning of this critical molar mass remains unclear [17]. Indeed, in addition to a decrease of the molar mass associated with chain scission phenomena, an increase of the crystallinity ratio which also promotes embrittlement is also witnessed. This latter process is often called the chemi-crystallization process [17]. The contributions of the two mechanisms, both promoting embrittlement, is intricate to unravel.

In the case of the chemical ageing of PEKK, a clear understanding of the relationships between these chain scission and/or crosslinking mechanisms and the loss of ductility remains a challenge to be faced to establish the relevant modifications limiting the so-called polymer end of life for a given long-term exposure. We propose here to investigate the embrittlement of a PEKK 70/30 occurring during exposure at $280^{\circ} \mathrm{C}$. This temperature of exposure has been chosen to balance between a temperature high enough to initiate detectable oxidative ageing, knowing the PEKK is highly stable from the oxidation point of view, and a temperature below the melting peak onset. As a result, we report here for the first time a comprehensive study of the PEKK embrittlement in an oxidative atmosphere by characterizing the polymer at microscopic scales. Chemical modifications and kinetic aspects will be investigated in a second article.

\section{Experimental}

The as-received material used for this study is a poly(ether ketone ketone) (subsequently named PEKK 70/30) film of $50 \mu \mathrm{m}$ in an amorphous state provided by Arkema. Terephthaloyl (T) and Isophthaloyl (I) are the two moieties in the monomers used for the synthesis of PEKK 70/30. For this copolymer, the T/I ratio is $70 / 30$. Pieces of PEKK films with dimensions of $5 \times 10 \mathrm{~cm}^{2}$ were cut and put on Teflon sheets in perforated aluminum boxes in a ventilated oven at $280^{\circ} \mathrm{C}$. The boxes were taken from the oven periodically with exposure times from $24 \mathrm{~h}$ to $1200 \mathrm{~h}$ and cooled in ambient atmosphere while the cover of the box was closed. The 24 h sample (cold crystallized) was considered as the unaged reference sample. All films with different exposure times were ana- lyzed similarly with different methods from macroscopic to molecular scales.

At the macroscopic scale, the mechanical behavior of exposed films was analyzed by tensile tests using a tensile machine (Instron 4301). Dumbbell samples with dimensions of $2 \times 10 \mathrm{~mm}^{2}$ in the gauge length were cut out of the exposed films by using a sharpened punch, having the main axis aligned with the extrusion direction of the films. Tests were done at room temperature with the strain rate of $1 \mathrm{~mm} / \mathrm{min}$ on 4-6 samples for each exposure time.

At the macromolecular scale, all samples with different exposure times were analyzed by Differential Scanning Calorimetry (DSC), Dynamic Mechanical Analysis (DMA), Small and Wide-Angle X-Ray Scattering (SAXS-WAXS), and Gel Permeation Chromatography (GPC).

DSC analyses were carried out on a TA Instruments Q1000 calorimeter with ca. $8 \mathrm{mg}$ of each sample sealed in a hermetic aluminum pan. The thermal analysis is divided into three stages consisted of a first heating, a cooling, and a second heating with similar heating and cooling rates of $10^{\circ} \mathrm{C} / \mathrm{min}$ under nitrogen flow (50 $\mathrm{mL} / \mathrm{min})$. In the first heating, the sample was equilibrated at $20^{\circ} \mathrm{C}$ and heated up to $400^{\circ} \mathrm{C}$. The sample was then maintained for 5 minutes at $400^{\circ} \mathrm{C}$. In the cooling stage, the sample was cooled down to $20^{\circ} \mathrm{C}$ and, then, was maintained for 1 minute to equilibrate. In the second heating, the sample was subsequently heated up to $400^{\circ} \mathrm{C}$.

DMA analyses were done using a TA Instruments Q800 dynamic mechanical analyzer on samples with dimensions of $5 \times 10 \mathrm{~mm}^{2}$ that were cut out of the main exposed pieces using a press machine and a mobile punch. The tension mode with an oscillation strain of $0.1 \%$ was used at $1 \mathrm{~Hz}$. Each sample was equilibrated at $-130^{\circ} \mathrm{C}$ for 2 minutes, then it has been heated up to $300^{\circ} \mathrm{C}$ with a heating rate of $3^{\circ} \mathrm{C} / \mathrm{min}$.

Simultaneous Small and Wide Angle X-rays Scattering experiments were performed on the Xenocs Nano-inXider SW system in transmission mode using $\mathrm{Cu} K \alpha$ radiation $(\lambda=1.54 \AA)$ from an X-ray microsource (GeniX3D) operating at $50 \mathrm{kV}-0.6 \mathrm{~mA}(30 \mathrm{~W})$. Scattering patterns were collected using the combination of two Pilatus3 (Dectris) detectors operating simultaneously in SAXS and WAXS positions allowing a continuous q range between $0.01 \AA^{-1}$ and $4.2 \AA^{-1}$ ( $2 \theta$ range between $0.15^{\circ}$ and $62^{\circ}$ ). From SAXS spectra, we calculated the electron density function using the XSACT software [18] and deduced the crystalline lamellae thickness $\mathrm{L}_{\mathrm{c}}$ and periodicity $L_{P}$. We decomposed WAXS spectra in crystalline and amorphous components using Fityk software [19] and deduced the crystalline phase and the weight crystalline ratio. The detailed procedure used for the SAXS-WAXS quantitative analysis was published in previous publications [20,21].

GPC measurements were performed by Arkema on a Waters Alliance 2695 device with a Waters 2414 RID detector.

\section{Results}

First, we propose to put in evidence mechanical behavior changes during exposure at $280^{\circ} \mathrm{C}$ in air. Second, we investigate all modifications that can be responsible for these mechanical changes.

\subsection{Mechanical property changes}

Fig. 1 shows the evolution of the elongation at break for PEKK $70 / 30$ as a function of ageing time. Inset shows typical strain-stress curves of selected tensile test experiments at three ageing duration, i.e. $24 \mathrm{~h}, 300 \mathrm{~h}$, and $1000 \mathrm{~h}$. The ductility of PEKK is unaltered at very short times. However, as exposure duration reaches a critical value of $300 \mathrm{~h}$, the elongation at break decreases. At $400 \mathrm{~h}$ 


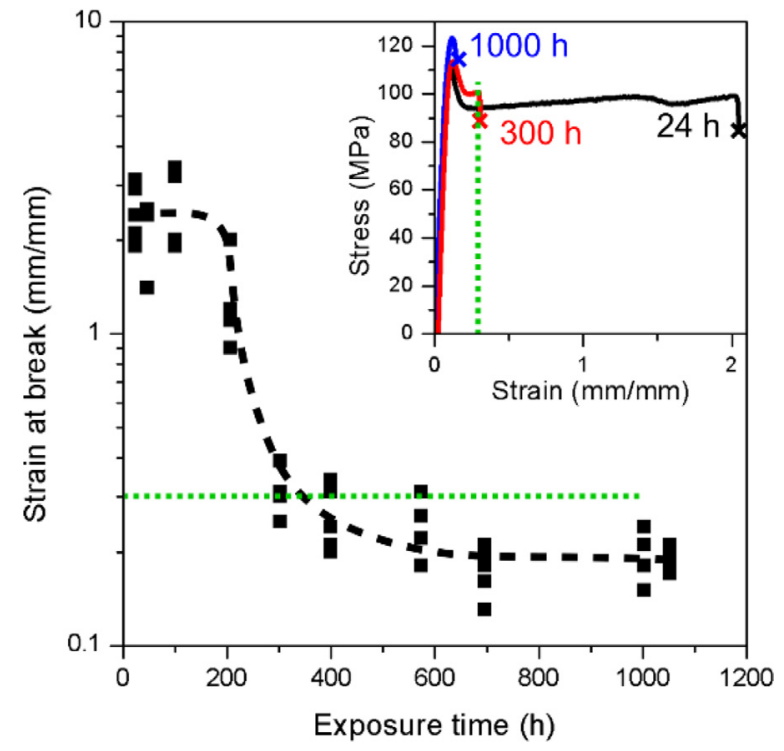

Fig. 1. Strain at break of PEKK $70 / 30$ as a function of exposure time at $280^{\circ} \mathrm{C}$. The black dotted line is a guide to the eye. The green dotted line represents strain at break of $30 \%$. Inset shows typical stress-strain curves of selected aged PEKK samples exposed at $280^{\circ} \mathrm{C}$ for $24 \mathrm{~h}, 300 \mathrm{~h}$, and $1000 \mathrm{~h}$. (For interpretation of the references to color in this figure legend, the reader is referred to the web version of this article).

of exposure, the material shows low ductility since failure occurs when the necking process is initiated. We define an arbitrary criterion at 30\% (green dotted line), below which PEKK loses its ductility. For very long exposure times, strain at break tends to an asymptotic value close to the yield strain value i.e. $10 \%$. We can note that properties at small strain such as Young's modulus is not significantly affected by ageing (results are not shown here).

If this embrittlement process is usual for polymers under oxidative atmosphere, we propose here to investigate by a multi-scale approach the physico-chemical reasons for such behavior. As seen in the introduction, this kind of embrittlement process can be associated with several causes such as molecular mobility modifications, especially sub-glass transitions, molar mass changes, or crystallinity increase. In the next parts, we propose to investigate experimentally each cause.

\subsection{Molecular mobility}

Dynamic mechanical analysis (DMA) remains the best way to investigate molecular mobility changes during ageing. This classical tool enables the characterization of local/sub-glass mobility and cooperative/glass transition. Fig. 2 represents the DMA results obtained for a selected set of PEKK samples exposed at $280^{\circ} \mathrm{C}$. It shows the evolution of the storage modulus and the $\tan (\delta)$ as a function of temperature (from $-120^{\circ} \mathrm{C}$ to $260^{\circ} \mathrm{C}$, from glassy to rubbery states). $\operatorname{Tan}(\delta)$ curves include mechanical manifestation of the glass transitions indicated by strong peaks at temperatures higher than $150^{\circ} \mathrm{C}$ and sub-glass transitions manifested by numerous weaker peaks at temperature mainly below $0^{\circ} \mathrm{C}$.

The intensity of sub-glass transitions would be greater in shear mode but it requires thicker samples [9]. However, DMA in elongation mode was preferred since samples are films in order not to have DLO oxidation. This mode was used to characterize oxidized epoxy films in a recent publication [14] and a clear modification of the sub-glass transition was observed. In the case of PEKK films in elongation mode, the sub-glass transition is weak, especially in dry conditions [9], compare to that of the epoxy systems in the same experimental conditions. As a result, it is difficult to conclude

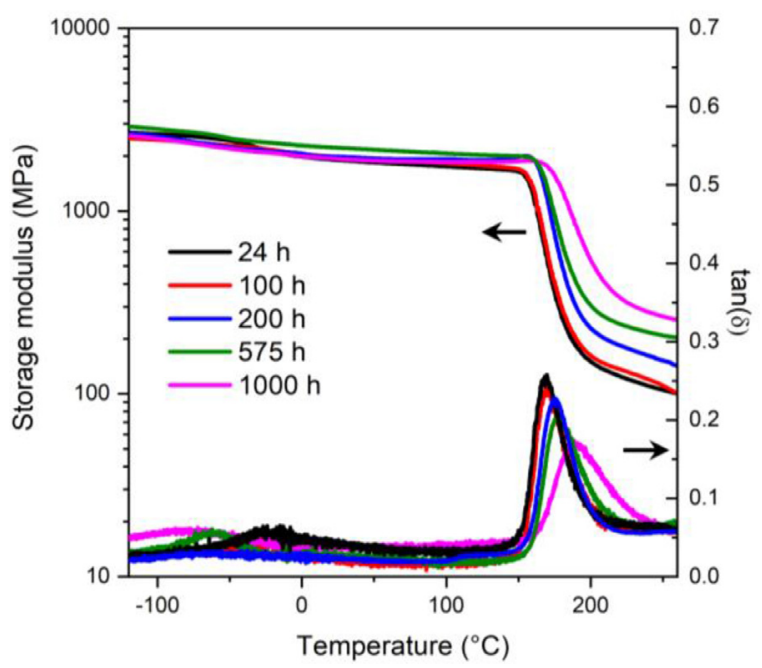

Fig. 2. Evolution of the storage modulus (left axis) and $\tan (\delta)$ (right axis) as a function of temperature for PEKK $70 / 30$ exposed at $280^{\circ} \mathrm{C}$ during $24 \mathrm{~h}, 100 \mathrm{~h}, 200 \mathrm{~h}$, $575 \mathrm{~h}$, and $1000 \mathrm{~h}$.

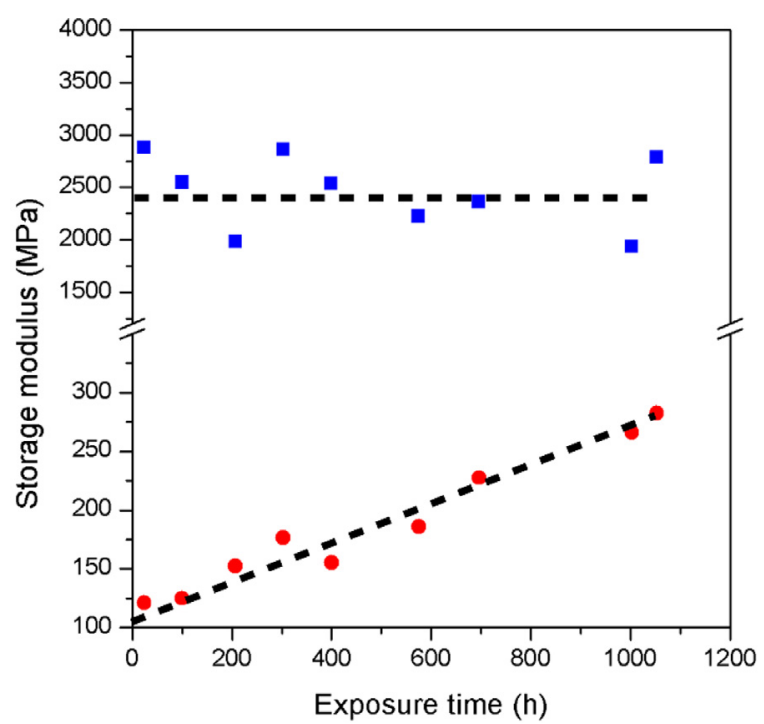

Fig. 3. Evolution of the storage modulus E' as a function of exposure time at $23^{\circ} \mathrm{C}$ (upper half) and $250^{\circ} \mathrm{C}$ (lower half).

about the impact of the degradation on the sub-glass transition. On the other hand, by increasing the exposure time, the maximum of the alpha peak indicating the mechanical manifestation of the glass transition $\left(\mathrm{T}_{\alpha}\right)$ shifts to higher values. As the exposure time goes by, the intensity of the glass transition peak decreases while the basal width of the peak increases. This basal width increase could be attributed to a wider distribution of relaxation times, which could be interpreted as an increase of dynamical heterogeneities around the alpha transition [22]. The increase of $\mathrm{T}_{\alpha}$ as a result of increasing the exposure time suggests that crosslinking occurs predominantly but a chain scission process cannot be excluded. The same conclusion has been drawn for similar exposure in the case of PEEK where $\mathrm{T}_{\mathrm{g}}$ changes has been witnessed [23].

Storage modulus curves as the other group of curves in Fig. 2, are composed of glassy state, which ends with the modulus dropping at the rubbery state. If the modulus measured below $\mathrm{T}_{\alpha}$ is almost indifferent to the exposure time, one can witness that $\mathrm{T}_{\alpha}$ increases with exposure time whereas rubbery modulus increases. More precisely, Fig. 3 shows the evolution of the storage modulus at room temperature $\left(\mathrm{T}<\mathrm{T}_{\alpha}\right)$ and at $250^{\circ} \mathrm{C}\left(\mathrm{T}>\mathrm{T}_{\alpha}\right)$ extracted 

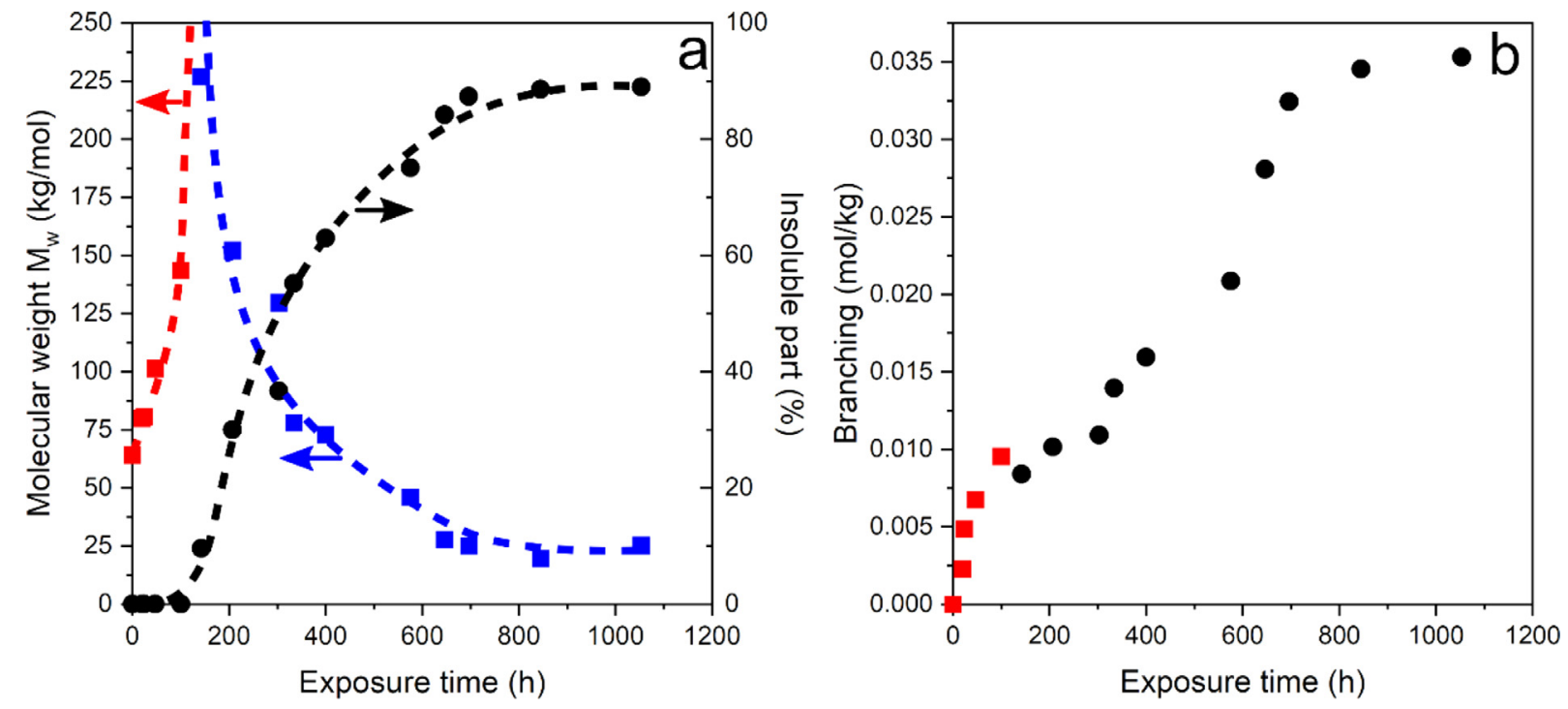

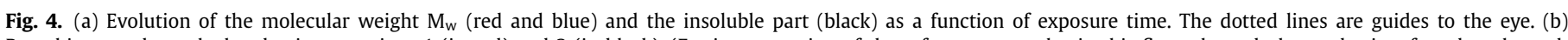

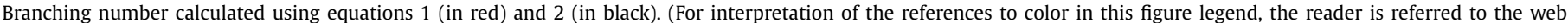
version of this article).

from modulus curves in Fig. 2. The magnitude of the modulus in the glassy state remains almost constant while it increases in the rubbery state as the exposure time elapses. This increase in rubbery modulus value measured above $\mathrm{T}_{\alpha}$ can be associated with an increase of the crystallinity or to a crosslinking process. This point will be investigated later.

\subsection{Macromolecular modifications}

Fig. 4a shows the evolution of the molar mass $M_{w}$ as well as the percentage of insoluble part obtained by GPC as a function of exposure time at $280^{\circ} \mathrm{C}$. Until $125 \mathrm{~h}$ of exposure, the samples are totally soluble in the GPC solvent and the molar mass (red) increases. Thereafter, the molar mass of the soluble part (blue) drops while the insoluble part (black) increases. The increase of the molar mass in the first stage, followed by insoluble fraction formation, undoubtedly confirms a predominant branching/crosslinking process. Given that $\mathrm{M}_{\mathrm{w}}$ increases sharply from the very beginning, the number of chain scissions (s) can be considered as minor compared to branching/crosslinks (x).

In order to assess the crosslinking mechanism during the exposure, we propose to apply Saito theory [24] valid up to the gel point $(100 \mathrm{~h})$ where crosslinks are easily related to weight average molar masses as follows:

$2 x=\frac{1}{M_{w}}-\frac{1}{M_{w 0}}$

After the gel point, Charlesby-Pinner theory [25] can be used with the insoluble fraction data knowing the initial molar mass $\mathrm{M}_{\mathrm{w} 0}$ and by considering that chain scissions are negligible:

sol $+\sqrt{\text { sol }}=\frac{1}{x M_{w 0}}$

In Fig. 4b, we report the cross-linking number during exposure before gel point thanks to Saito theory and after the gel point according to Charlesby-Pinner theory. It appears clearly that the crosslinking process starts from the beginning of the exposure and crosslinking is the major degradation phenomenon, as it was also observed for PEEK $[23,26]$. It is noteworthy that crosslink number calculated by both ways is consistent before and after the gel point.

\subsection{Crystallization aspects}

Fig. 5 shows DSC thermograms in first heating on the left (a) and cooling on the right (b). Sigmoid-shape signals around $150^{\circ} \mathrm{C}$ to $200^{\circ} \mathrm{C}$ in both groups of thermograms are the manifestation of glass transition. Since the mechanical manifestation of the glass transition has been more clearly discussed in the DMA part, we will focus here on the melting and crystallization behavior.

In Fig. 5a, the melting peak for the sample with an exposure time of $24 \mathrm{~h}$ is wide and shows two shoulders on both sides of the minimum, which indicates either different crystalline phases or lamellae thicknesses. As ageing is increased to $100 \mathrm{~h}$, a stronger melting peak appears with shoulders above this melting temperature. As the exposure time increases, the shoulders are not visible anymore due to the shift of the melting peak to higher temperatures, as seen for the $200 \mathrm{~h}$ sample, for which only a sharp peak is observed. For exposure times of $300 \mathrm{~h}$ to $1000 \mathrm{~h}$ this peak sharpens and as time goes by, the melting temperature increases.

The first heating was followed by a cooling stage (at $10^{\circ} \mathrm{C} / \mathrm{min}$ ). In Fig. 5b, crystallization peaks emerges during cooling at temperatures higher than $200^{\circ} \mathrm{C}$. For exposures below $200 \mathrm{~h}$, chains have a considerable mobility and crystallize in a great amount so that crystallization appears with an exothermic peak during cooling. For exposure above $300 \mathrm{~h}$, crystallization seems to be limited: whereas the crystallization temperature drops, the crystallization exotherm is flattened. For exposure of 1000 h, chains do not crystallize significantly, as the crystallization kinetics becomes too slow compared to the applied cooling ramp.

Fig. 6 shows the evolution of the heat of melting as a function of exposure time, measured during the first and second heating. In the first heating, the heat of melting increases for the first hundred hours and then stabilizes as the exposure time increases. In the second heating section following the cooling stage at $10^{\circ} \mathrm{C} / \mathrm{min}$, the heat of melting decreases almost linearly from the very beginning of exposure until $800 \mathrm{~h}$ to become almost negligible. In other words, the increase of the heat of melting during the first heating reflects an annealing process that can be associated with a chemicrystallization mechanism. In this case, chains initially trapped in the amorphous region by the entanglement network, can be released and then incorporated in the crystalline phase. Knowing this mechanism requires a chain scission mechanism, we can conclude 

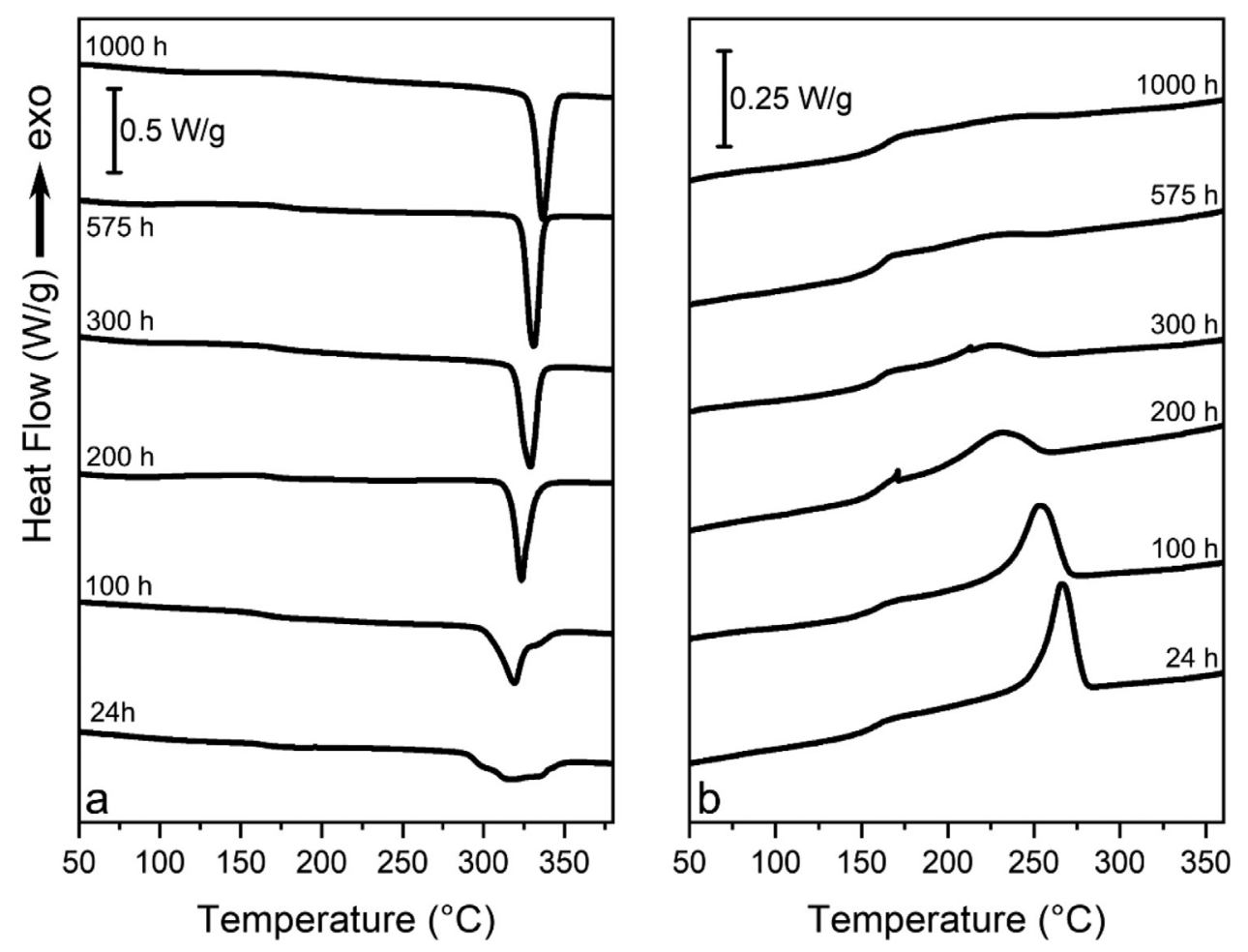

Fig. 5. First heating (a) and cooling (b) DSC thermograms of PEKK $70 / 30$ exposed at $280^{\circ} \mathrm{C}$ for times ranging from 24 to 1000 h.

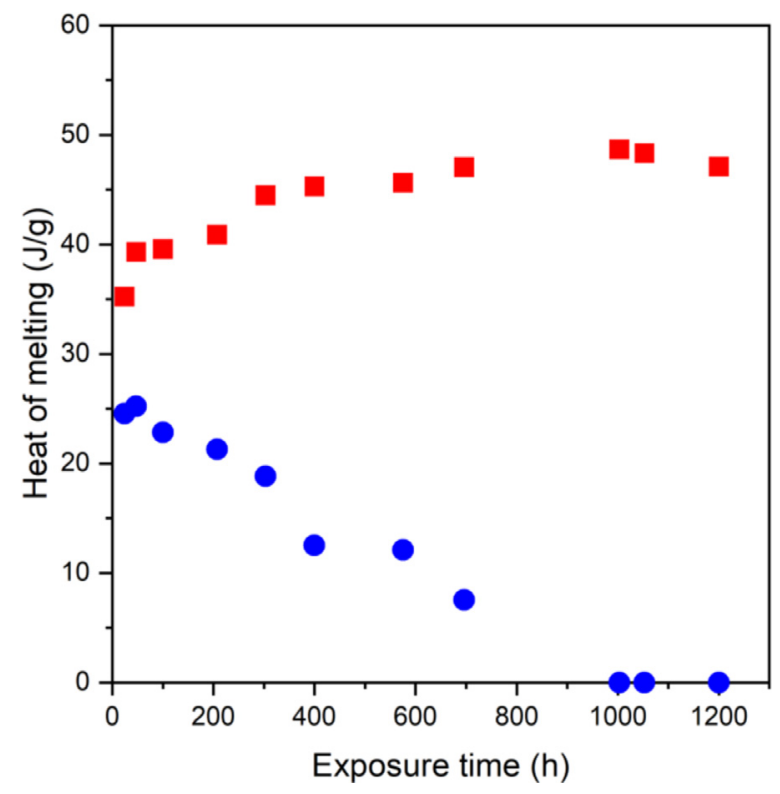

Fig. 6. Evolution of the heat of melting measured during the first heating ( $\mathbf{\square})$ and the second heating $(\bullet)$ as a function of exposure time.

that even if the crosslinking mechanism is predominant, a chain scission mechanism should occur simultaneously. The fact that the crosslinking mechanism is predominant is confirmed by the decrease of the enthalpy of melting measured during the second heating, since the resulting crosslinks no longer allow the crystallization process to proceed. This latter phenomenon is often observed in semi-crystalline polymers in which crosslinking is the main degradation mode as was observed for PEEK under irradiation [27].
It is well known that PEKK copolymers exhibit a polymorphism depending on their chemical composition, namely the T/I ratio, and their crystallization kinetics and pathway [3]. WAXS and SAXS measurements were performed in order to check possible crystalline modifications, nature, and amount, during the exposure at $280^{\circ} \mathrm{C}$. Fig. 7 shows diffraction spectra for samples aged at different exposure times. After $24 \mathrm{~h}$ at $280^{\circ} \mathrm{C}$, the film sample, which was initially amorphous, underwent a cold crystallization and can be considered as fully crystallized [8].

As the initial film is amorphous, the samples have been cold crystallized during the thermal treatment at $280^{\circ} \mathrm{C}$. It is known that cold crystallization of PEKK, with T/I around 70/30, leads to coexistence of form I and form II while melt crystallization yields to mostly form I [28]. In Fig. 7a, both form I and form II are indeed observed. Each Bragg peak is indexed with the (hkl) planes of the crystal lattices of form I and form II, respectively [4,21]. The ageing does not seem to impact the polymorphism distribution as the diffractograms remain unchanged even until $1000 \mathrm{~h}$.

The decomposition of the WAXS spectra in crystalline and amorphous components leads to the calculation of the weight crystallinity ratios [20]. Fig. 8 shows the evolution of this weight crystalline ratio as a function of exposure time. The crystallinity ratio increases significantly from 0.22 to 0.28 after $1200 \mathrm{~h}$ of exposure time.

We recorded simultaneously WAXS and SAXS signals. Scattering at small angle (SAXS), reported in Fig. 7b, characterizes the crystalline lamellae organization. From these SAXS curves, we can calculate the correlation function of the electronic density and deduce the crystalline lamellar thickness $\left(\mathrm{L}_{\mathrm{C}}\right)$ and periodicity $\left(\mathrm{L}_{\mathrm{P}}\right)$ [20]. These data are reported in Fig. 8. For exposure time below $200 \mathrm{~h}$, we observe a slight increase of the lamellar thickness, from $31 \AA$ to $33 \AA$, while the periodicity remains constant at $126 \AA$. For higher exposure time, $\mathrm{L}_{\mathrm{P}}$ decreases first to $118 \AA$ at $700 \mathrm{~h}$ then remains constant beyond, while $\mathrm{L}_{\mathrm{c}}$ decreases slowly and continuously until 1200 h to reach $30 \AA$. 

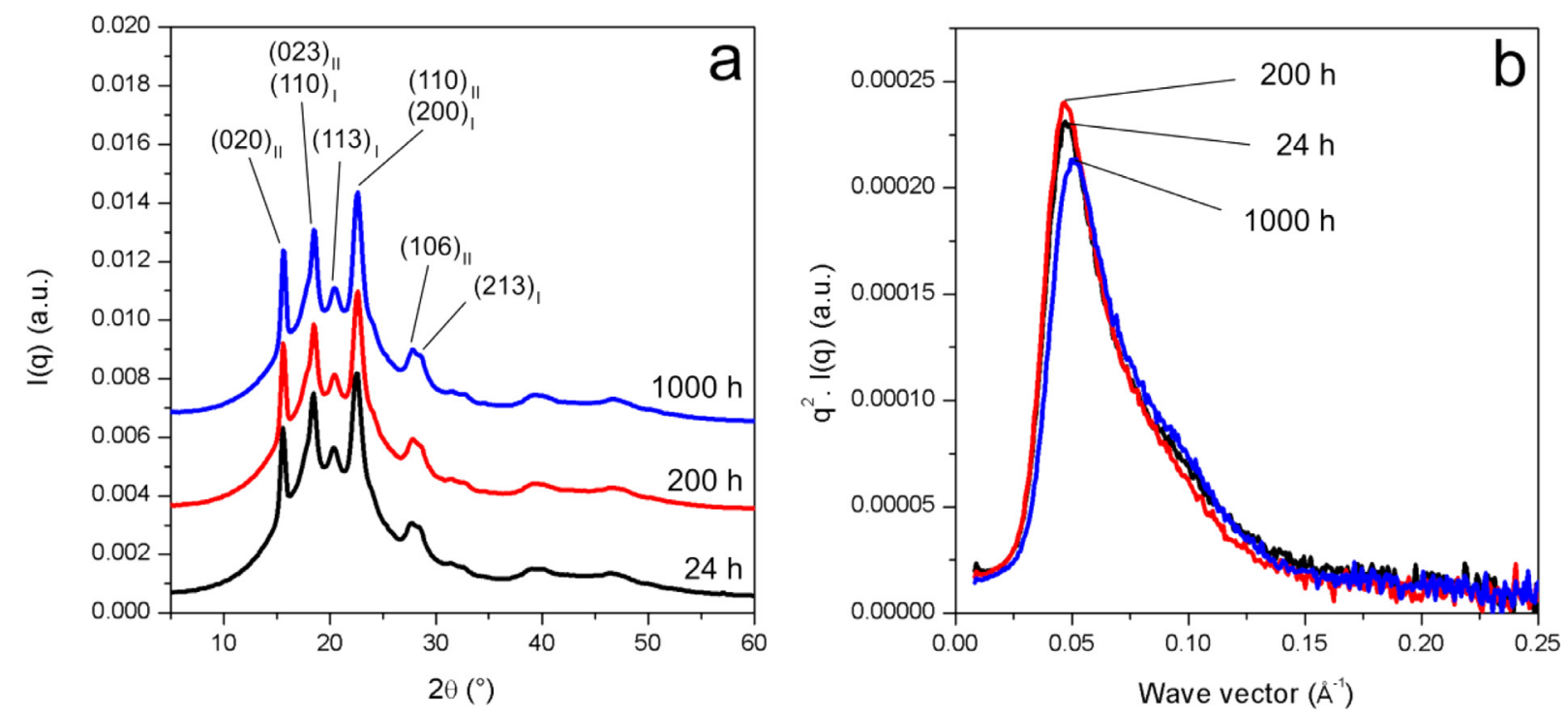

Fig. 7. WAXS (a) and SAXS (b) spectra for PEKK $70 / 30$ exposed at $280^{\circ} \mathrm{C}$ for $24 \mathrm{~h}, 200 \mathrm{~h}$, and $1000 \mathrm{~h}$.

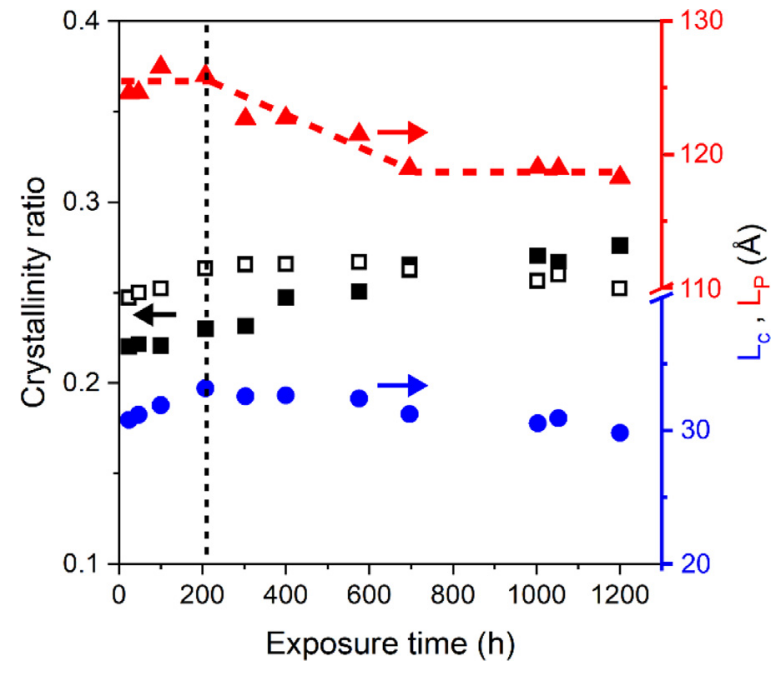

Fig. 8. Weight crystallinity ratio from WAXS ( $\square$ ) and volume crystallinity ratio $\left(\mathrm{L}_{\mathrm{C}} / \mathrm{L}_{\mathrm{P}}\right)$ from SAXS $(\square)$ as a function of exposure time at $280^{\circ} \mathrm{C}($ left $), \mathrm{L}_{\mathrm{C}}(\bullet)$ and $L_{P}(\boldsymbol{\Lambda})$ from SAXS.

If all the crystalline and the amorphous phases are localized into the lamellae stacks, then the $\mathrm{L}_{C} / \mathrm{L}_{\mathrm{P}}$ ratio represents a volume crystal ratio. This data, reported in Fig. 8, evolves only very slightly: a first increase below $200 \mathrm{~h}$ is followed by a plateau between $200 \mathrm{~h}$ and $600 \mathrm{~h}$ before a small decrease.

\section{Discussion}

In this part, we focus on structure-mechanical property relationships, which could explain the properties changes observed during degradation. As we have seen, both phases of the polymer are impacted by the degradation: scission/crosslinking in the amorphous phase and crystalline lamellae modifications, which effects are still to be accounted for.

\subsection{Amorphous and crystalline phase changes}

From DSC and WAXS, we measure a significant increase of the weight crystallinity ratio from $22 \%$ to $28 \%$ for exposure times between $24 \mathrm{~h}$ and $1200 \mathrm{~h}$. On the other hand, the volume crys- tallinity does not evolve significantly. This difference can be attributed to the amorphous density modification as a result of branching/crosslinking [29-31]. Indeed, the evolution of the long period $L_{P}$ (Fig. 8), well correlated with the branching number (Fig. 4b), mainly reflects an evolution of the amorphous phase thickness. For low exposure times, there is no significant branching, $L_{P}$ remains constant. For exposure times between $200 \mathrm{~h}$ and $700 \mathrm{~h}$, the number of branching and crosslinks increases drastically while $\mathrm{L}_{P}$ decreases from $126 \AA$ to $118 \AA$. In the meantime, we also observe that the lamellar thickness $\mathrm{L}_{c}$ remains almost unchanged with exposure time. The slight increase of $\mathrm{L}_{\mathrm{c}}$ until $200 \mathrm{~h}$ could be interpreted as a small annealing process, which might be related to the chain scission mechanism. At the beginning of ageing, even though the chain scission processes are minor, they are effective enough to produce chemi-crystallization while crosslinking/branching acts are not sufficient enough to prevent this phenomenon. Consequently, $\mathrm{L}_{c}$ slightly increases from the beginning of ageing. As ageing proceeds (after vertical dashed line at ca. $200 \mathrm{~h}$ ), crosslinking/branching acts become more effective, which prevents the chemi-crystallisation from pursuing. This would explain how $\mathrm{L}_{\mathrm{c}}$ reaches a plateau after $200 \mathrm{~h}$.

\subsection{Modulus changes}

We have seen in Fig. 3 that if the modulus at $23^{\circ} \mathrm{C}$ remains constant, the modulus measured at $250^{\circ} \mathrm{C}$, i.e. above $\mathrm{T}_{\mathrm{g}}$, increases from 120 to $270 \mathrm{MPa}$ during the degradation process. The first possible origin of this increase can be ascribed to the crosslinking mechanism since the crosslink number $(v)$ after $1000 \mathrm{~h}$ of exposure, reaches a value close to $0.03 \mathrm{~mol} . \mathrm{kg}^{-1}$ (Fig. $4 \mathrm{~b}$ ). However, if we assess that the rubbery modulus of the amorphous phase increases only up to $0.4 \mathrm{MPa}$ thanks to the rubbery theory $\mathrm{E}=3 \times v \times \mathrm{RT} \rho$ with volumic mass $\rho$ at $250^{\circ} \mathrm{C}(623 \mathrm{~K})$ of $1.17 \mathrm{~g} . \mathrm{cm}^{-3}$ [32], it is obvious that the crosslinking process can not contribute to the modulus increase. The second possible origin of the modulus increase is the crystallinity change. We have seen in Fig. 8 that the crystallinity is significantly modified. In order to ascertain a possible correlation between both quantities, the storage modulus measured at $250^{\circ} \mathrm{C}\left(\mathrm{T}_{\mathrm{g} 0}{ }^{\mathrm{DMA}}+80^{\circ} \mathrm{C}\right)$ is plotted as a function of crystallinity measured by WAXS in Fig. 9. A clear trend is evidenced and confirms qualitatively the dependence of the modulus on the crystallinity. To examine more quantitatively the physical meaning of this dependence, we can compare these data with the data 


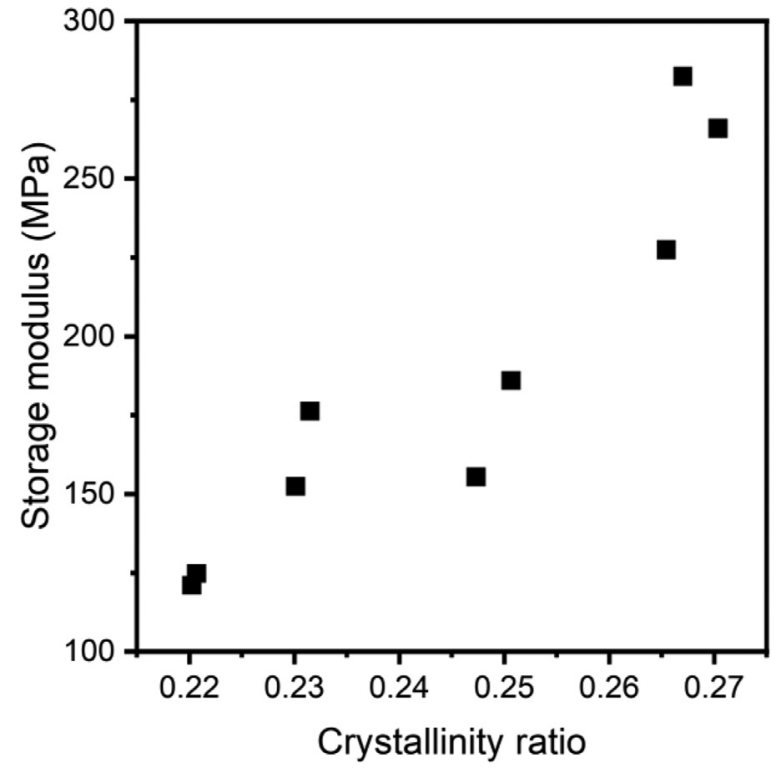

Fig. 9. Storage modulus measured at $250^{\circ} \mathrm{C}$ as a function of the crystallinity ratio measured by WAXS.

shown in Choupin et al. [12] where PEKK (60/40) tensile modulus measured higher than $T_{g}\left(180^{\circ} \mathrm{C}\right)$ is related to crystallinity. In this study, the crystallinity in terms of melting enthalpy was modified by varying the crystallization conditions. Even though it is complicated to compare directly these data, since the experimental conditions (DMA vs. static tensile testing) are not similar, it appears that the modulus dependence relates to what was observed by Choupin et al. and we can conclude that the increase of the modulus above $\mathrm{T}_{\mathrm{g}}$ is clearly related to crystallinity.

\subsection{A mixed criterion for the ductility loss during ageing}

In Fig. 1, the green dotted line represents an arbitrary criterion that delimits the high and the low ductility regions. As this ductility loss is clearly evidenced during the exposure at $280^{\circ} \mathrm{C}$ in air, we propose here to discuss all modifications that can be responsible for this change of mechanical property. According to the literature seen in the Introduction part, different modifications associated with chemical ageing have been proposed to understand the loss of ductility of polymers:

i Local (molecular sub-glass) mobility decrease

ii Crosslinking leading to limited chain extensibility

iii Chain scission leading to a reduction of the molar mass below a critical value $\mathrm{M}_{\mathrm{C}}$, related to the molar mass between entanglements

iv Crystallinity increase or crystalline morphology change in the case of semi-crystalline polymers

Our investigations in the case of PEKK 70/30 under air show that the first mechanism (i) appears to be irrelevant since the subglass transition is not impacted by the ageing process. However, considering that this mechanism only concerns amorphous polymers, the presence of a crystalline phase in our case could also hide this mechanism.

Macromolecular modifications, i.e. crosslinking and/or chain scissions, have been investigated by different ways: $T_{g}$, molar mass, and gel fraction increase, which clearly indicates that crosslinking is largely predominant over chain scission. The crystallization behavior confirms this process since new crosslinks avoid chain folding and thus crystals formation. However, could this crosslinking process limit the extensibility of chains into the amorphous phase,

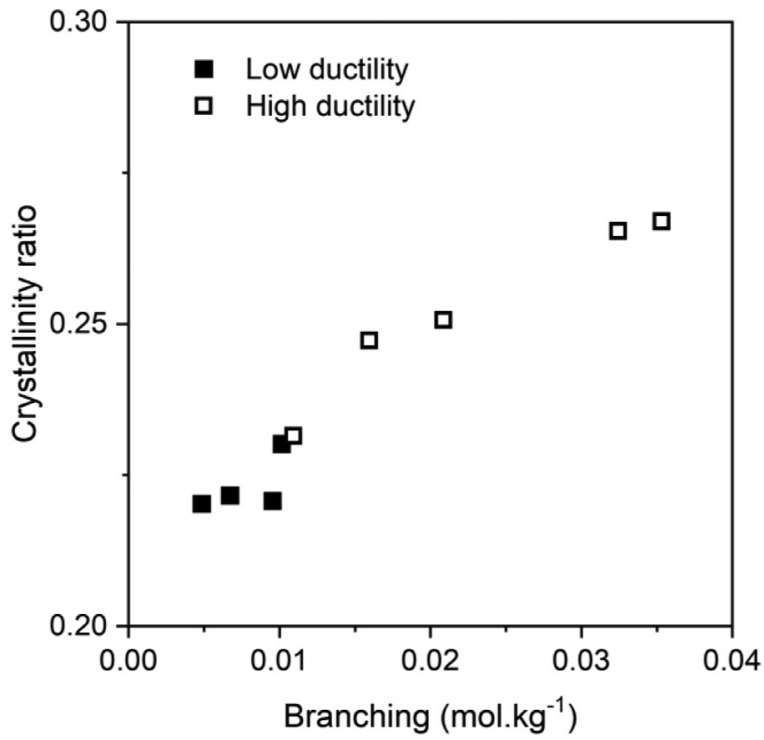

Fig. 10. Crystallinity ratio - branching map for the loss of ductility.

which could reduce the strain at break? This scenario is often discussed for elastomers having different crosslinking density [33]. For instance, the proportional relation $\lambda_{\text {fail }} \propto v^{-1 / 2}$ has been proposed, where $\lambda_{\text {fail }}$ is the elongation at break [34]. In our case, the fact that $\lambda_{\text {fail }}$ is inversely proportional to $v$ is consistent to this latter scenario.

The second scenario is to consider that embrittlement is mainly governed by the crystallinity ratio, as for the modulus. As it has been proposed in a review devoted to semi-crystalline polymers [17], embrittlement due to chain scission process, the ductilebrittle transition results in an increase of the crystallinity ratio corresponding to a decrease of the amorphous thickness: below a critical value, a cavitation process initiated in the amorphous zone would be promoted during the deformation over plasticity leading a macroscopic brittle failure. In our case, we also observe a decrease of the amorphous thickness. However, this decrease could be assessed to a densification of the amorphous phase rather than an increase of the crystalline thickness.

As a result, during the degradation, the predominant crosslinking is accompanied with a chemi-crystallization process. To compare the two scenarios (branching/crosslinking vs. crystallinity ratio), Fig. 10 was plotted. As can be seen in this figure, the change in crystallinity is so little that it cannot be accounted for the loss of ductility. Thus, we consider that the main reason to explain this loss should be the branching/crosslinking acts that must be even more effective at a temperature below $\mathrm{T}_{\mathrm{g}}$, since the molecular mobility is limited. In order to test this criterion, different ways of chemical degradation could be performed such as different temperatures of exposure or irradiation conditions.

\section{Conclusions}

In this study, the thermo-oxidative degradation at elevated temperatures $\left(280^{\circ} \mathrm{C}\right)$ below the melting temperature of PEKK $70 / 30$ has been evidenced. A prominent branching/crosslinking process has been identified at the molecular level, as both the molar mass and the glass temperature transition increase with exposure time. A chain scission process cannot be totally excluded as chemi-crystallization is suspected through the evolution of the degree of crystallization. The DSC and the WAXS analyses indicate an increase of the crystallization that can be caused most probably through a minor chain scission process. This increase in crys- 
tallinity can be correlated to the increase of the modulus above the glass transition temperature. Overall, the observed loss of ductility of aged PEKK 70/30 is in all likelihood induced by a branching/crosslinking process occurring in the amorphous phase impeding the molecular mobility during the plasticization at large deformation.

\section{Declaration of Competing Interest}

The authors declare that they have no known competing financial interests or personal relationships that could have appeared to influence the work reported in this paper.

\section{CRediT authorship contribution statement}

Sébastien Roland: Writing - review \& editing, Supervision, Conceptualization, Visualization. Mahdi Moghaddam: Writing - original draft, Investigation. Sylvie Tencé-Girault: Writing - review \& editing, Supervision, Conceptualization, Investigation. Bruno Fayolle: Writing - review \& editing, Supervision, Conceptualization, Project administration, Funding acquisition.

\section{Acknowledgments}

The authors acknowledge the financial support of the French National Research Agency (ANR IMPEKKABLE project). The authors wish to thank the LEM laboratory (Arkema, Serquigny), especially Sylvie Lebreton and François Bargain for facilitating SAXSWAXS experiments and Christine Thieulin and Stéphane Bizet for GPC measurements. Stéphane Bizet and Benoît Brulé are warmly thanked for fruitful discussion, reading, and clarifying this article. We would also like to thank Rakhi Sood for some experimental parts in this work. This work was performed within the framework of the Industrial Chair Arkema (Arkema/CNRS-ENSAM-Cnam).

\section{References}

[1] K.H. Gardner, B.S. Hsiao, R.R. Matheson, B.A. Wood, Structure, crystallization and morphology of poly (aryl ether ketone ketone), Polymer 33 (1992) 24832495, doi:10.1016/0032-3861(92)91128-0.

[2] I.Y. Chang, PEKK as a new thermoplastic matrix for high-performance composites, Sampe Q. 19 (1988) https://www.osti.gov/biblio/6888352.

[3] S.Z.D. Cheng, R.-M. Ho, B.S. Hsiao, K.H. Gardner, Polymorphism and crystal structure identification in poly(aryl ether ketone ketone)s, Macromol. Chem. Phys. 197 (1996) 185-213, doi:10.1002/macp.1996.021970115.

[4] R.-M. Ho, S.Z.D. Cheng, B.S. Hsiao, K.H. Gardner, Crystal morphology and phase identification in poly(aryl ether ketone)s and their copolymers. 3. Polymorphism in a polymer containing alternated terephthalic acid and isophthalic acid isomers, Macromolecules 28 (1995) 1938-1945, doi:10.1021/ ma00110a030.

[5] B.S. Hsiao, I.Y. Chang, B.B. Sauer, Isothermal crystallization kinetics of poly(ether ketone ketone) and its carbon-fibre-reinforced composites, Polymer 32 (1991) 2799-2805, doi:10.1016/0032-3861(91)90111-U.

[6] M. Cai, M. Zhu, P. Wang, C. Song, Synthesis and properties of novel poly(aryl ether ketone)s containing both diphenyl moiety and amide linkages in the main chains, Polymer 51 (2010) 1293-1300, doi:10.1016/j.polymer.2010.01.041.

[7] E. Dan-Jumbo, R. Keller, B. Westerman, A. Kuraishi, S.W. Tsai, J. Wang, in: Life Prediction of Carbon Fiber/PEKK Thermoplastic Composite Material for Structures Design, Memphis, TN, 2008, p. 16.

[8] T. Choupin, B. Fayolle, G. Régnier, C. Paris, J. Cinquin, B. Brulé, A more reliable DSC-based methodology to study crystallization kinetics: application to poly(ether ketone ketone) (PEKK) copolymers, Polymer 155 (2018) 109-115, doi:10.1016/j.polymer.2018.08.060.

[9] M. Coulson, L. Quiroga Cortés, E. Dantras, A. Lonjon, C. Lacabanne, Dynamic rheological behavior of poly(ether ketone ketone) from solid state to melt state, J. Appl. Polym. Sci. 135 (2018) 46456, doi:10.1002/app.46456.
[10] L. Quiroga Cortés, N. Caussé, E. Dantras, A. Lonjon, C. Lacabanne, Morphology and dynamical mechanical properties of poly ether ketone ketone (PEKK) with meta phenyl links, J. Appl. Polym. Sci. 133 (2016) n/a-n/a, doi:10.1002/ app.43396.

[11] L. Benedetti, B. Brulé, N. Decreamer, K.E. Evans, O. Ghita, Shrinkage behaviour of semi-crystalline polymers in laser sintering: PEKK and PA12, Mater. Des. 181 (2019) 107906, doi:10.1016/j.matdes.2019.107906.

[12] T. Choupin, L. Debertrand, B. Fayolle, G. Régnier, C. Paris, J. Cinquin, B. Brulé, Influence of thermal history on the mechanical properties of poly(ether ketone ketone) copolymers, Polym. Cryst. (2019), doi:10.1002/pcr2.10086.

[13] L. Monnerie, J.L. Halary, H.-H. Kausch, Deformation, yield and fracture of amorphous polymers: relation to the secondary transitions, in: H.-H. Kausch (Ed.), Intrinsic Mol. Mobil. Toughness Polym. I, Springer-Verlag, Berlin/Heidelberg, 2005, pp. 215-372, doi:10.1007/b136957.

[14] E. Ernault, E. Richaud, B. Fayolle, Origin of epoxies embrittlement during oxidative ageing, Polym. Test. 63 (2017) 448-454, doi:10.1016/j.polymertesting.2017. 09.004.

[15] E.J. Kramer, Microscopic and molecular fundamentals of crazing, in: H.H. Kausch (Ed.), Crazing Polym, Springer-Verlag, Berlin/Heidelberg, 1983, pp. 1-56, doi:10.1007/BFb0024055.

[16] B. Fayolle, L. Audouin, J. Verdu, A critical molar mass separating the ductile and brittle regimes as revealed by thermal oxidation in polypropylene, Polymer 45 (2004) 4323-4330, doi:10.1016/j.polymer.2004.03.069.

[17] B. Fayolle, E. Richaud, X. Colin, J. Verdu, Review: degradation-induced embrittlement in semi-crystalline polymers having their amorphous phase in rubbery state, J. Mater. Sci. 43 (2008) 6999-7012, doi:10.1007/s10853-008-3005-3.

[18] XSACT: X-ray scattering analysis and calculation tool. SAXS \&WAXS Data Analysis Software-Version 0.19.3. Available onlin, (n.d.).

[19] M. Wojdyr, Fityk : a general-purpose peak fitting program, J. Appl. Crystallogr. 43 (2010) 1126-1128, doi:10.1107/S0021889810030499.

[20] S. Tencé-Girault, S. Lebreton, O. Bunau, P. Dang, F. Bargain, Simultaneous SAXSWAXS Experiments on Semi-Crystalline polymers: example of PA11 and its brill transition, Crystals 9 (2019) 271, doi:10.3390/cryst9050271.

[21] S. Tencé-Girault, J. Quibel, S. Roland, B. Fayolle, S. Bizet, I. Iliopoulos, Quantitative Structural Study of Cold Crystallized PEKK, Submitt. Macromol. (n.d.).

[22] R.J. Masurel, S. Cantournet, A. Dequidt, D.R. Long, H. Montes, F. Lequeux, Role of dynamical heterogeneities on the viscoelastic spectrum of polymers: a stochastic continuum mechanics model, Macromolecules 48 (2015) 66906702, doi:10.1021/acs.macromol.5b01138.

[23] E. Courvoisier, Y. Bicaba, X. Colin, Multi-scale and multi-technique analysis of the thermal degradation of poly(ether ether ketone), Polym. Degrad. Stab. 151 (2018) 65-79, doi:10.1016/j.polymdegradstab.2018.03.001.

[24] O. Saito, H.Y. Kang, M. Dole, Theory of gel-dose curves for polymers undergoing simultaneous crosslinking and scission, J. Chem. Phys. 46 (1967) 36073616, doi: $10.1063 / 1.1841265$.

[25] A. Charlesby, S.H. Pinner, Analysis of the solubility behaviour of irradiated polyethylene and other polymers, Proc. R. Soc. Lond. Ser. Math. Phys. Sci. 249 (1959) 367-386, doi:10.1098/rspa.1959.0030.

[26] P. Patel, T.R. Hull, R.E. Lyon, S.I. Stoliarov, R.N. Walters, S. Crowley, N. Safronava, Investigation of the thermal decomposition and flammability of PEEK and its carbon and glass-fibre composites, Polym. Degrad. Stab. 96 (2011) 12-22, doi:10.1016/j.polymdegradstab.2010.11.009.

[27] T. Sasuga, H. Kudo, Ion irradiation effects on thermal and mechanical properties of poly(ether-ether-ketone) (PEEK), Polymer 41 (2000) 185-194, doi:10. 1016/S0032-3861(99)00143-3.

[28] K.H. Gardner, B.S. Hsiao, K.L. Faron, Polymorphism in poly(aryl ether ketone)s, Polymer 35 (1994) 2290-2295, doi:10.1016/0032-3861(94)90763-3.

[29] C.J. Chen, D.C. Boose, G.S.Y. Yeh, Radiation-induced crosslinking: II. Effect on the crystalline and amorphous densities of polyethylene, Colloid Polym. Sci. 269 (1991) 469-476, doi:10.1007/BF00655884.

[30] Z. Kacarevic-Popović, D. Kostoski, L.J. Novaković, Effect of gamma irradiation on density and thermal expansion changes of uniaxially oriented linear lowdensity polyethylene, Radiat. Phys. Chem. 55 (1999) 645-648, doi:10.1016/ S0969-806X(99)00262-5.

[31] A.K. Mukherjee, P.K. Tyagi, B.D. Gupta, Effect of gamma radiation on low density polyethylene, Angew. Makromol. Chem. 161 (1988) 77-87, doi:10.1002/ apmc.1988.051610108.

[32] C. Li, A. Strachan, Prediction of PEKK properties related to crystallization by molecular dynamics simulations with a united-atom model, Polymer 174 (2019) 25-32, doi:10.1016/j.polymer.2019.04.053.

[33] F. Bueche, J.C. Halpin, Molecular theory for the tensile strength of gum elastomers, J. Appl. Phys. 35 (1964) 36-41, doi:10.1063/1.1713095.

[34] T.L. Smith, Ultimate tensile properties of elastomers. III. Dependence of the failure envelope on crosslink density, Rubber Chem. Technol. 40 (1967) 544555, doi: $10.5254 / 1.3539068$. 